Clin Geriatr Med. 2014 August ; 30(3): 629-654. doi:10.1016/j.cger.2014.04.008.

\title{
Substance Abuse Among Older Adults
}

\author{
Alexis Kuerbis, LCSW, PhDa, ${ }^{\star}$, Paul Sacco, PhD, LCSWb, Dan G. Blazer, MD, PhDc, and \\ Alison A. Moore, MD, MPH \\ aDepartment of Mental Health Services and Policy Research, Research Foundation for Mental \\ Hygiene, Inc, Columbia University Medical Center, 3 Columbus Circle, Suite 1404, New York, NY \\ 10019, USA \\ bUniversity of Maryland School of Social Work, 525 West Redwood Street, Baltimore, MD 21201, \\ USA
}

'Department of Psychiatry and Behavioral Sciences, Academic Development, Duke University, DUMC 3003, Durham, NC 27710, USA

dDepartment of Medicine, Division of Geriatrics, David Geffen School of Medicine at UCLA, 10945 Le Conte Avenue, Suite 2339, Los Angeles, CA 90095, USA

\section{Keywords}

Older adults; Alcohol; Prescription medication; Substance use; Assessment; Assessment tools; Brief interventions; Treatment

\section{INTRODUCTION}

The initial wave of the baby boom generation turned 65 years old in 2011, a generation that comprises $30 \%$ of the total US population. ${ }^{1}$ The size of this generation and their longer life expectancies $^{2}$ led the US Census Bureau to project that the number of older adults will increase from 40.3 million to 72.1 million between 2010 and $2030 .{ }^{3}$ Historically, older adults have not demonstrated high rates of alcohol or other drug use compared with younger adults ${ }^{4,5}$ or presented in large numbers to substance abuse treatment programs. ${ }^{6}$ These facts have helped to perpetuate a misconception that older adults do not use or abuse moodaltering substances. Indeed, substantial evidence suggests that substance use among older adults has been underidentified ${ }^{7,8}$ for decades. The aging of the baby boom generation creates a new urgency to effectively identify and treat substance use among older adults.

Baby boomers are distinct compared with past generations as they came of age during the 1960s and 1970s, a period of changing attitudes toward and rates of drug and alcohol use. ${ }^{9,10}$ The prevalence rates of substance use disorder (SUD) have remained high among this group as they age,${ }^{5}$ and both the proportions and actual numbers of older adults needing treatment of SUD are expected to grow substantially. SUD rates among people older than 50 years are projected to increase from about 2.8 million in 2006 to 5.7 million in $2020 .^{11}$

(C) 2014 Elsevier Inc. All rights reserved.

*Corresponding author. alexis.kuerbis@gmail.com. 
There is, therefore, widespread recognition among both generalists and specialists in gerontology and psychiatry, $, 12,13$ and health care overall, of the need for more information about assessment and interventions related to problematic substance use among older adults.

\section{PREVALENCE OF SUBSTANCE USE AMONG OLDER ADULTS}

Alcohol Use-Despite increasing rates of illicit and prescription drug misuse among adults older than 65 years,, ,6,10 alcohol remains the most commonly used substance among older adults. ${ }^{6,10}$ Therefore, most of the research on substance use among and treatment of older adults has centered on alcohol use disorders (AUD). Among the population at large, older adults reduce their alcohol use as they age. ${ }^{14-17}$ As of 2002, among individuals aged 65 years and older in the general population, the estimated prevalence is $1.2 \%$ for the Diagnostic and Statistical Manual of Mental Disorders (Fourth Edition) (DSM-IV) alcohol abuse and $0.24 \%$ for $D S M-I V$ alcohol dependence. ${ }^{18}$ Prevalence estimates inclusive of those older than 50 years are higher (2.98\% for all AUD). Within heath care settings, the rates of AUD among older adults ranges up to a proportion of $22 \% .{ }^{19-21}$ Although these rates are lower than for younger adults, they are likely impacted by the underreporting of heavy drinking, ${ }^{7}$ difficulties with differential diagnoses of AUDs in older adults, and unidentified comorbidities. $^{22}$

At-risk drinking is more prevalent among older adults than AUD and is likely responsible for a larger share of the harm to the health and well-being of older adults. Guidelines provided by the American Geriatrics Society and the National Institute for Alcohol Abuse and Alcoholism recommend that older adults drink no more than 7 standard drinks (12-oz beer, 4- to 5-oz glass of wine, $1.5 \mathrm{oz}$ of 80 -proof liquor) per week. ${ }^{10,16}$ Prevalence rates for older-adult at-risk drinking (defined as more than 3 drinks on one occasion or more than 7 drinks per week) are estimated to be $16.0 \%$ for men ${ }^{23,24}$ and $10.9 \%$ for women. ${ }^{20,21}$ There is also a substantial proportion of the older-adult population who are binge drinkers (generally defined as 5 or more standard drinks in one drinking episode, though definitions vary for older adults). ${ }^{25}$ Rates of older-adult binge drinking are $19.6 \%$ for men and $6.3 \%$ for women using data from the 2005-2006 National Survey on Drug Use and Health. ${ }^{20,26}$ In a study of community-based older adults who reported drinking one or more drinks in the previous 3 months, $67 \%$ reported binge drinking in the last year. ${ }^{25}$

Tobacco Use-Tobacco use is quite prevalent among older adults, with about $14 \%$ of those aged 65 years and older reporting tobacco use in the last 12 months, ${ }^{10}$ and just more than $6 \%$ used tobacco and alcohol together in the last 12 months. Clinical trials examining smoking cessation interventions demonstrate that older-adult smokers tend to be long-term, heavy smokers who are also physiologically dependent on nicotine. ${ }^{27-29}$

Illicit Substance Use-Illicit drug use is more prevalent among American older adults than among older adults in almost any other country in the world. ${ }^{30}$ Results from the 2012 National Survey on Drug Use and Health revealed that rates of past month use of illicit substances doubled on average (from 1.9\%-3.4\% to 3.6\%-7.2\%) among 50 to 65 year olds between 2002 and $2012^{5}$ — a statistically significant increase driven by the baby boom generation..$^{5,11}$ Generally, individuals aged 50 to 64 years report more psychoactive drug use 
than older groups. ${ }^{24,31,32}$ For example, in 2012, 19.3\% of adults aged 65 years and older reported having ever used illicit drugs in their lifetime, whereas $47.6 \%$ of adults between 60 and 64 years of age reported lifetime drug use. Among those that do use illicit substances, $11.7 \%$ meet the criteria for past-year SUD. ${ }^{31}$ There are no recommendations for safe levels of illicit drug use among older adults. ${ }^{33}$

Cannabis use by older adults is considerably more prevalent than other drugs. Among adults aged 50 years and older in 2012, 4.6 million reported past-year marijuana use, and less than one million reported cocaine, inhalants, hallucinogens, methamphetamine, and/or heroin use in the past year. These rates are consistent with those reported by other studies. ${ }^{24,31}$ With the passage of medical marijuana legislation and relaxed enforcement of drug possession related to marijuana, the prevalence rate of use among older adults may increase as they use it to cope with illness-related side effects, ${ }^{20}$ potentially facilitating an increase in recreational use.

Prescription, Nonprescription, and Over-the-Counter Medication Use-Older adults take more prescribed and over-the-counter medications than younger adults, ${ }^{22,34}$ increasing the risk for harmful drug interactions, misuse, and abuse. A cross-sectional community-based study of 3005 individuals aged 57 to 85 years found that $37.1 \%$ of men and $36.0 \%$ of women used at least 5 prescription medications concurrently. ${ }^{35}$ The study also found that about 1 in 25 of the participants were at risk for a major drug interaction, and half of these situations involved nonprescription medications. In 2012, 2.9 million adults aged 50 years and older reported nonmedical use of psychotherapeutic medications in the past year. ${ }^{5}$ Estimates of prescription medication misuse among older women are $11 \% .{ }^{36}$ Blazer and $\mathrm{Wu}^{32}$ reported that $1.4 \%$ of adults aged 50 years and older used prescription opioids nonmedically in the last year, which was higher than sedatives, tranquilizers, and stimulants (all $<1 \%$ ). Actual prescription opioid use disorder among this same group was $0.13 \%$, yet dependence was more common than abuse. ${ }^{31}$ Benzodiazepines are the most commonly prescribed psychiatric medication among all adults. Despite contraindications for use with older adults, they are widely prescribed ${ }^{37}$ and are disproportionately prescribed to older adults. ${ }^{38}$ Rates of benzodiazepine use among older adults have ranged from $15.2 \%$ to $32.0 \% .{ }^{39}$ It is important to note that the rates of benzodiazepine use may be impacted by overprescription, misdiagnosis, or polypharmacy rather than intentional misuse or abuse.

\section{UNIQUE VULNERABILITIES FOR OLDER ADULTS USING MOOD-ALTERING SUBSTANCES}

Although the rates of SUD and use of drugs and alcohol are generally lower among older adults than the general population, aging itself presents specific risks for harm when considering even minimal amounts of substance use among older adults. Risk factors may vary considerably by substance and the specific clinical presentation of a patient (eg, age, medical comorbidities, current medications, and health history). Understanding substancespecific risks can help practitioners to recognize and respond to unhealthy use that does not meet the narrow definition of problem use. 


\section{Alcohol}

Alcohol has a unique physical impact on the body in late life as compared with adults in young to middle age. ${ }^{40}$ As one ages, the percentages of lean body mass and total body water decrease, and the ability of the liver to process alcohol is also diminished; blood-brain barrier permeability and neuronal receptor sensitivity to alcohol in the brain increase. ${ }^{22}$ Because of these changes, older adults experience higher blood alcohol concentrations and increased impairment compared with younger adults ${ }^{40}$ at equivalent consumption levels and with less awareness of their impairment, ${ }^{41-43}$ thus, rendering them more vulnerable to the ill effects of alcohol even in moderate amounts. Compared with moderate drinkers, older-adult at-risk drinkers are more likely to experience alcohol-related problems ${ }^{14,25}$ and basic functional impairment, such as impaired instrumental activities of daily living (eg, shopping, cooking, responsibility for medication). ${ }^{25}$ The increased rate of comorbid medical and psychiatric conditions and the medications used to treat them create a complicated picture of risk and unique vulnerabilities for older adults. ${ }^{10}$ Even healthy drinking levels established in young to middle age and then sustained through older age may be a risk factor for health problems among older adults. ${ }^{44}$

Despite the older person's increased vulnerability to alcohol, moderate alcohol consumption is associated with decreased morbidity and mortality among older adults. ${ }^{45,46} \mathrm{~A}$ large body of research suggests that those older adults who are moderate drinkers (no more than one standard drink per day) experience better health than their heavier drinking and abstinent peers. ${ }^{4-49}$ For example, moderate-drinking older adults have been discovered to have fewer falls, greater mobility, and improved physical functioning when compared with nondrinkers. ${ }^{40}$

It is important to note that many of the health benefits of moderate alcohol use for older adults may come with negative trade-offs. For example, moderate drinking may decrease the risk of ischemic stroke but increase the risk of hemorrhagic stroke $\mathrm{e}^{50}$ and have many potential interactions with medications. ${ }^{51}$ As with other age groups, it would seem that the benefits of alcohol for older adults varies across individuals and depends on each person's unique biopsychosocial context, including age, comorbid illnesses, sex, and genetics.

\section{Medications and Illicit Drugs}

The same biologic changes that increase the effect of alcohol among older adults also increase the effect of medications and illicit drugs, causing an increased vulnerability to drug effects and drug interactions. ${ }^{22}$ For example, older adults process benzodiazepines and opiates differently than younger adults; these medications should be prescribed with caution. Benzodiazepines with long half-lives are contraindicated for older adults as they can cause excessive sedation. ${ }^{36}$ Benzodiazepines are fatsoluble drugs; as adults have less lean muscle mass and more body fat as they age, these drugs have a longer duration of action. Other risks associated with medication use in older adults occur because they may see multiple doctors, each of who may prescribe them medications that may interact with each other and/or with alcohol or other substances. Alcohol and marijuana increase the sedative effects of drugs such as barbiturates, benzodiazepines, and opiates. ${ }^{52}$ Older adults may also unintentionally misuse a medication by borrowing a prescribed medication from another person (eg, taking 
a dose of another person's lorazepam or zolpidem for sleep), taking more than intended, or confusing pills.

The increasing acceptance of marijuana use, both medicinally and recreationally, may also pose unique risks in an aging population. Marijuana is known to cause impairment of shortterm memory; increased heart rate, respiratory rate, elevated blood pressure; and a 4-time increase in the risk for heart attack after the first hour of smoking marijuana. ${ }^{53}$ These risks may be pronounced in older adults whose cognitive or cardiovascular systems may already be compromised. Additionally, tobacco use among older adults is associated with greater mortality, risks of coronary events and cardiac deaths, smoking-related cancers, chronic obstructive pulmonary disease, decline in pulmonary function, development of osteoporosis, risk of hip fractures, loss of mobility, and poorer physical functioning. ${ }^{54,55}$ Incidentally, smoking also impairs or inhibits effective treatments for these conditions. ${ }^{56}$ It is unclear which of these correlates to smoking tobacco also appear for marijuana. ${ }^{53}$

\section{RISK FACTORS FOR OLDER ADULTS USING SUBSTANCES}

Most research on the correlates and predictors of substance use in late life has been conducted on alcohol use. Individual, social, and familial factors that contribute to or are associated with late-life unhealthy drinking may also apply to other substances. Box 1 lists some of the potential risk factors for older adults associated with use of alcohol and, where known, other substances.

\section{Demographics}

Being male, ${ }^{23}$ more affluent, ${ }^{20,57,58}$ Caucasian, ${ }^{23,59}$ and young-old (those in the early stages of late life $)^{23}$ are consistently associated with unhealthy drinking in late life. Among all the demographics that are associated with increased drinking, only one is a predictor of increased drinking in older age: having more financial resources or longer financial horizons. ${ }^{57,58}$ Female sex is associated with prescription drug abuse. ${ }^{36}$

\section{Physical and Mental Health}

Both current alcohol use and unhealthy drinking in older age are associated with being in better overall health ${ }^{23,57}$; however, this does not imply a causal relationship but rather suggests that those in good health are apt to drink more than their counterparts in poor health. Indeed, drinking has been shown to decrease as hospitalizations, disabilities, or depression increase. ${ }^{23,60,61}$ Importantly, across studies, older heavy drinkers demonstrate poorer physical and mental health $23,40,61,62$ as compared with their low-risk drinking counterparts. Drinking to reduce pain is a crucial long-term predictor of alcohol use in older adulthood. $^{58}$

Because comorbid psychiatric disorders, such as anxiety, depression, and personality disorders, are common and recognized among younger adults, it is assumed that these comorbidities also continue into late life. Although there is little research about psychiatric comorbidity with substance use among older adults, some evidence suggests there is a high correlation between substance use, specifically alcohol use, and depression ${ }^{63,64}$ and other affective disorders ${ }^{33,65}$ among older adults. ${ }^{66,67}$ The co-occurrence of depression and AUD 
can greatly complicate the diagnosis and treatment of both. For example, older adults may be more likely to disclose depressive symptoms and present to primary care settings rather than mental health or substance abuse treatment settings.

Sleep disturbance and sleep disorders are common among older adults who use alcohol ${ }^{68}$ and who may use alcohol as a sleep aid. ${ }^{33}$ Concurrent use of alcohol and medications for insomnia is risky because of drug interaction effects that cause excessive sedation and crosstolerance. The factors associated with prescription medication abuse in older adults include a history of a SUD or mental health disorder and medical exposure to prescription drugs with abuse potential. ${ }^{36}$ There is also evidence to suggest that overall cognitive impairment and several different types of dementia are more prevalent among older adults with comorbid alcohol use disorders ${ }^{22,25,69,70}$ and that the differential diagnosis between Alzheimer disease and alcohol-related dementia is difficult. ${ }^{33}$

Among comorbid SUD, alcohol and tobacco are used commonly together among older adults ${ }^{10}$; being a smoker increases the likelihood of being an at-risk drinker. ${ }^{71}$ Little else is known about the use patterns among older adults and the use of multiple substances simultaneously.

\section{Coping Style}

An individual's coping style for stress or tension may predict the development of a drinking problem in late life. An analysis of the Health and Retirement Study revealed that individuals who relied on avoidance coping to deal with stress or solve problems had a greater likelihood of developing and maintaining a late-life drinking problem than those who coped in other ways. ${ }^{57}$ Similarly, a community-based survey of older adults who had contact with an outpatient health care facility found that relying on substances to reduce tension was associated with having a late-life alcohol problem. ${ }^{72}$

\section{History of Alcohol Problems}

There are a few studies that identified a history of problem drinking as a risk factor for unhealthy drinking among older adults. Platt and colleagues ${ }^{57}$ found there was a significant increase in the likelihood of increasing one's drinking in later life among older adults with a history of drinking problems who did not abstain. Another longitudinal study of a community-based sample found that having drinking problems by 50 years of age significantly increased the likelihood of drinking and/or unhealthy drinking in late life. ${ }^{58}$

\section{Social Factors}

Some social factors are consistently associated with late-life drinking. Being divorced, separated, or single is positively associated with increased or unhealthy drinking in late life, ${ }^{10,23}$ though this may differ across sexes. Social contact with friends or close family members among residents of retirement communities was found to be associated with increased alcohol use. ${ }^{73}$ In this same study, a lack of religious affiliation was also found to be associated with higher categorical levels of drinking, each of which were defined by an increase in quantity and frequency of drinking. Although increased social interaction is 
associated with drinking among older adults, social isolation is associated with prescription drug abuse. ${ }^{36}$

Certain life events and social transitions common in late life may also heighten the risk of substance use or misuse. For example, bereavement (death of spouse, family, or friends), physical ill health, loneliness, caregiving for an ill spouse, change in living arrangement, and loss of occupation can all be factors in the substance use of older adults. ${ }^{74-77}$ A review of the impact of retirement on older-adult drinking revealed that preretirement conditions, such as high job satisfaction or workplace stress, seem to increase the overall use of and problems with alcohol after retirement. ${ }^{78}$ In addition, involuntary retirement and broadened social networks after retirement increase the likelihood of increased alcohol consumption or drinking problems. ${ }^{78,79}$ Finally, housing status or living situation can facilitate or sustain substance use. For example, homelessness has been found to be a correlate of late-life drinking problems ${ }^{69,80}$; substance use among older adults has also been found to continue and even be enabled in the context of nursing homes. ${ }^{81-83}$

\section{DIAGNOSIS}

The formal diagnosis of SUD in the general population generally relies on the criteria outlined by the $D S M .{ }^{84,85}$ Table 1 outlines several symptoms of SUD based on physical and/or social factors. Because of particular biologic and social factors unique to late life, these criteria may be less relevant to older adults. This circumstance presents unique challenges for an accurate diagnosis of SUD among older adults. ${ }^{16}$ For example, because of the age-associated physiologic changes that increase the effects of alcohol and other substances, older adults generally experience a reduction of tolerance to these substances, thus interfering with one of the hallmarks of SUD, increased tolerance. Furthermore, interruption in social and vocational roles or other consequences of drinking or drug use may be less likely to occur or less noticeable in old age. ${ }^{44,86}$ Aging is often associated with a natural departure from these roles, such as through retirement ${ }^{78}$ or social isolation caused by mortality of age-group peers. ${ }^{87}$ Furthermore, the criterion related to continued use despite persistent or recurrent problems may not apply to many older adults who do not recognize that their problems, such as depression, are related to drinking. ${ }^{16}$

Using the Item Response Theory with 2009 National Survey on Drug Use and Health data, one study explored whether there were age-related biases among the criteria for AUD. ${ }^{86}$ The findings revealed that there were differential responses among older versus middle-aged adults, such that older adults were half as likely as middle-aged adults to endorse the criteria related to tolerance, activities to obtain alcohol, social/ interpersonal problems, and physically hazardous situations. The criteria that were most successful in discriminating AUD among older adults were unsuccessful efforts to cut back, withdrawal, and social and interpersonal problems. With the release and adoption of DSM-5, a wider proportion of older adults will likely be classified as having SUD than under the DSM-IV criteria; however, a large proportion will likely remain unidentified. ${ }^{86}$

As a result of these diagnostic problems, many who study substance abuse in older adults de-emphasis the reliance on $D S M$ criteria to identify problematic substance use requiring 
intervention. Instead, they use a 2-tier categorical classification: at risk and problem use of substances (Table 2). ${ }^{16}$ At-risk substance use (also referred to as excessive use or hazardous use $)^{33}$ is characterized by those who use substances above the recommended or prescribed levels but who experience few or no physical, mental, emotional, or social problems as a result of use. These individuals may be at high risk for the development of such problems and, therefore, still merit thorough screening and secondary prevention.

Problem substance use is characterized by those individuals who are already experiencing problems in the aforementioned areas as a result of their use. Identification of problem use among older adults does not depend on the quantity and frequency of use but on the context in which substances are used. For example, older adults may experience extreme problems with alcohol even when ingesting it at minimal levels because of medical conditions, such as gout or pancreatitis. Although the terms at risk and problem use are extremely useful in settings such as primary care, they can pose difficulties in helping older adults access more formal treatment, as third-party payers often require formal SUD diagnoses to justify intensive or more lengthy treatments.

\section{SCREENING AND ASSESSMENT}

Historically, older adults are less likely to be screened for substance use. ${ }^{88,89}$ For example, in a study of 400 primary care physicians who were provided with a list of symptoms related to problematic substance use by a hypothetical older female patient, only $1 \%$ of physicians considered the possibility of a substance use problem. ${ }^{16}$ Although there is an increasing acceptance that older adults should be routinely screened for alcohol and other drug use or misuse, $3,12,35$ there are several factors that still inhibit screening and subsequent identification of risky alcohol or other drug use, including the limited time clinicians have to screen for several potential problems or illnesses; the potential stigma related to and discomfort assessing for addiction; the similarities of the symptoms of alcohol and other drug use with other illnesses common in later life ${ }^{69,90}$; and the common perception among older adults that symptoms experienced by the use of alcohol or drugs are seen as a part of normal aging rather than resulting from the substance use itself. ${ }^{91}$ Furthermore, older adults are known to have difficulty identifying their own risky behaviors around substance use, ${ }^{42}$ making the identification of such behavior even more difficult.

\section{Overall Considerations}

When assessing or speaking to older adults about substance use, some general considerations should apply. Older adults are known to respond more to a supportive, nonconfrontational approach than more assertive styles of assessment and intervention. ${ }^{92-94}$ Older adults are far more likely to provide information about potentially stigmatizing behaviors if they think that the clinician is genuinely interested in their overall health and well-being. ${ }^{44,90}$ Discussions of alcohol and other substance use should occur in the context of an overall assessment and in reference to the presenting problem with the goal of health promotion and a complete understanding of their health behaviors. Approaching the assessment with the goal of identifying a drug abuser is likely to stigmatize the older adult, engender defensiveness, and is inconsistent with the idea that any drug or alcohol use has the potential to be problematic. ${ }^{44}$ Therefore, in a gentle and respectful manner, detailed 
questions about quantity and frequency of drinking, medications (prescription and over the counter), and illicit drugs (especially marijuana) should be asked with the assumption that this information is important, whether the older adults' use is a problem or not. This reduces stigma by normalizing the behavior without endorsing it.

Many older adults, and even their families, view alcohol use as being their "one last pleasure, $" 83$ creating a complex picture of substance use in late life. In a study of alcoholdependent older adults at a Veteran Affairs medical center, older adults were found to be less strongly motivated to change their drinking than their younger counterparts, as they did not perceive their alcohol use as being particularly severe. ${ }^{95}$ For some older adults, a foreshortened sense of future may further inhibit motivation to reduce alcohol use. In addition, self-efficacy to reduce drinking may decline with age, ${ }^{96}$ depending on the level of control an older adult perceives in his or her life. ${ }^{91}$ In addition, low self-efficacy is related to fewer health-promotion behaviors among older adults because they perceive their physical limitations as an unavoidable component of aging. ${ }^{91}$

Box 2 reviews the potential symptoms or indicators of problematic substance use.

Assessments should start with questions about drinking, medication use, and illicit substances. The focus should be on the facts of substance use rather than questioning the person's judgment (eg, do you have a drinking or drug use problem?). ${ }^{44}$ During this discussion, questions about overuse and misuse can be included in a nonjudgmental way. ${ }^{44}$ For instance, asking a patient whether they sometimes take an extra pill to fall asleep or to cope with pain, run out of medication early, or borrow medications from others may provide important information and a gateway to further discussion about problematic use of substances. ${ }^{44}$ It should be noted that even if the older adult is currently abstinent from alcohol and other drugs, questions about use or misuse in the past are also important, as the answers may indicate increased vulnerability to other psychiatric disorders or cognitive decline. ${ }^{33}$

\section{Screening Tools}

Brief screening instruments can assess the level of risk caused by alcohol and drugs. Some screening tools are adaptations of instruments created for younger adults, and others have been designed for older adults. Interview screening tools or global selfreport measures are less intrusive or burdensome to the older adult than blood or urine tests. Furthermore, the use of biologic screening (ie, laboratory tests) has limited utility and can be problematic in older adults, as isolating impaired bodily functions (ie, liver function) as the result of alcohol or other substances versus prescribed medications may be difficult. Each of the instruments listed next have strengths and weaknesses related to resources required to implement them or applicability to older adults.

\section{CAGE-Adapted to Include Drugs (CAGE-AID)}

The most common screening tool for substance misuse is the CAGE questionnaire, which focuses on the potential for alcohol dependence. The CAGE was later adapted to assess for 
alcohol and other drugs and called the CAGE-AID. ${ }^{97}$ The CAGE-AID contains the following 4 questions:

1. Have you ever felt that you should Cut down on your drinking or drug use?

2. Have people Annoyed you by criticizing your drinking or drug use?

3. Have you ever felt bad or Guilty about your drinking or drug use?

4. Have you ever had a drink or used drugs first thing in the morning to steady your nerves or to get rid of a hangover (Eye opener)?

The questions can be adapted to a specific substance, such as a prescription medication, and they can be asked either in the context of an interview or self-administered. One or more positive responses are considered a positive screen. Psychometric properties of the CAGEAID have not been reported, yet the CAGE has been extensively studied. The CAGE has been validated in an older-adult population, demonstrating as high as $86 \%$ sensitivity and $78 \%$ specificity for a score of one or more ${ }^{56,98}$; however, the CAGE may identify a different group of drinkers than other measures, such as the Short Michigan Alcoholism Screening Test-Geriatric Version (SMAST-G), and it does poorly in detecting heavy and binge drinkers. ${ }^{99}$ Furthermore, it has not performed well in the psychiatric population. ${ }^{100}$ A major limitation of the CAGE-AID is that it does not distinguish between current and lifetime use, an especially difficult issue among the aging, who may have a history of problematic use without having a current problem. Because of the brief nature of the CAGE-AID, it can be a useful screening tool; but it should not be a substitute for a more thorough assessment, such as consumption levels, consequences of use, and functional deficits.

\section{The Michigan Alcohol Screening Test-Geriatric Version}

The Michigan Alcohol Screening Test-Geriatric Version (MAST-G) ${ }^{101}$ is an instrument designed to identify drinking problems and was developed specifically for the elderly by modifying the Michigan Alcohol Screening Test. This screening tool contains 24 questions with yes/no responses; 5 or more positive responses indicate problematic use. The MAST is highly sensitive and specific and generally has strong psychometric properties. ${ }^{102}$ It is also administered in a short form, the SMAST-G, which has 10 questions, with 2 positive responses indicating a problem with alcohol. Because of the diagnostic challenges outlined earlier, the MAST-G focuses more on potential stressors and behaviors relevant to alcohol use in late life, as opposed to questions toward family, vocational, and legal consequences of use. This tool has many of the advantages of the CAGE, such as ease of administration and low cost. It is also more specific than the CAGE in identifying problematic use. Although useful as an indicator of lifetime problem use, it lacks information about frequency, quantity, and current problems important for intervention.

\section{The Alcohol Use Disorders Identification Test}

Developed by the World Health Organization (WHO), the Alcohol Use Disorders Identification Test (AUDIT) assesses for current alcohol problems. ${ }^{103}$ The test consists of 10 questions pertaining to amount and frequency of use, alcohol dependency, and the consequences of alcohol abuse; it can be administered through an interview or self- 
administered. Each of the 10 questions is scored on a 4-point continuum, with total scores ranging from zero to 40 . The AUDIT was validated in older adults to detect problematic or hazardous use. ${ }^{104}$ Although the cutoff threshold to indicate AUD among a general population is 8 , a cutoff threshold of 5 was identified to indicate AUD among older adults. ${ }^{100,105}$ Five items on the AUDIT (items 1, 2, 4, 5, and 10) are particularly sensitive and specific to AUD among older adults and together have outperformed the full AUDIT and the CAGE. ${ }^{105}$

\section{The Alcohol, Smoking, and Substance Involvement Screening Test}

The Alcohol, Smoking, and Substance Involvement Screening Test (ASSIST) is another instrument developed by the WHO to screen across substances for potential problem use. ${ }^{106}$ It is an interview-based tool that consists of 8 questions that help identify the level of risk to help guide decisions for intervention. The ASSIST has yet to be validated among older adults, and there is at least anecdotal evidence that it underperforms in this population in part because of the same limitations with a formal DSM diagnosis; the criteria do not apply in the same way for older adults as they do with younger adults.

\section{The Comorbidity-Alcohol Risk Evaluation Tool}

The Comorbidity-Alcohol Risk Evaluation Tool (CARET) ${ }^{107}$ is a screening instrument whose precursor is the Short Alcohol Related Problems Survey. ${ }^{108}$ It identifies older adults who are at risk because of the quantity and frequency of their alcohol consumption, presence of comorbid diseases, high-risk behaviors (such as drinking and driving), and concomitant use of medications whose efficacy may be diminished or that may interact negatively with alcohol. It has demonstrated good face, content, and criterion validity with older adults. ${ }^{107-109}$ One of the strengths of the CARET is that it identifies hazardous alcohol use apart from simply the quantity and frequency of drinking, accounting for a wider spectrum of unhealthy use that could present dangers more common in later life. As a result, the CARET identifies at-risk or problem alcohol use among older adults with more sensitivity than the AUDIT and the MAST-G. ${ }^{107}$ Most older adults identified as at-risk drinkers using the CARET are identified as such because of their use of alcohol with medications. ${ }^{110}$

\section{INTERVENTIONS}

A continuum of treatment options are available for older adults, depending on the setting and the severity of the problems indicated. ${ }^{44}$ Contrary to the assumption that older substance users are stuck in permanent patterns of use, older adults have demonstrated treatment outcomes as good, or better, than those seen in younger groups ${ }^{111,112}$; however, access to specialized services tailored for older adults is limited. A national survey of substance abuse treatment programs found that only about $18 \%$ were specifically designed for older adults. ${ }^{44,113}$ Even if programs were available to them, overall, mental health utilization rates are lower among older adults than any other age group. ${ }^{39}$ Some of the barriers to specialized treatment that older adults face include stigma and shame surrounding substance use and related problems, geographic isolation, inability to pay, or difficulties with transportation. ${ }^{16,114}$ Interventions in nontraditional settings, such as emergency rooms, 
senior centers, and primary care offices, ${ }^{44,115}$ have been implemented in an attempt to reach vulnerable older adults outside the formal treatment system.

Because, in part, of the relative invisibility of older-adult substance use and SUD, relatively little published research exists on the efficacy and/or effectiveness of substance abuse treatment of older adults. ${ }^{112}$ In a recent review of research on substance abuse treatments for older adults, ${ }^{112}$ the researchers found a relative absence of published, rigorous, internally valid research. Therefore, the review of interventions discussed later is of those treatments for which there is some initial evidence of efficacy and/or effectiveness among this population.

\section{Brief Intervention}

Effective brief interventions ${ }^{110,116,117}$ occur in primary care settings, focus on alcohol and prescription medication misuse or abuse, and vary in length from 15 minutes to five 1-hour sessions. ${ }^{90,112}$ Their purpose is to provide education about the substance and how it might be harmful, enhance motivation for change, and connect severe users with more intensive treatments, ${ }^{42}$ when necessary. Normative feedback, in which a patient's drinking is compared with his or her peers, combined with brief advice is one of the most common brief interventions used and seems to be highly effective for older-adult drinkers. ${ }^{19,112,117}$

Most brief interventions are described as using aspects of motivational interviewing (MI) ${ }^{118}$ or motivational enhancement therapy (MET), ${ }^{119}$ which encourages a client-centered, nonjudgmental approach to discussing substance use and encouraging positive, healthy changes to the individual's life. Formal MI and MET aim to reduce ambivalence by assisting the client to identify in his or her own words the perceived pros and cons to making a change versus maintaining the status quo. ${ }^{44}$ For the older adult, the reasons for change may include maintaining independence, optimal health, and mental capacity. ${ }^{90}$ Although MI and MET are consistent with a nonconfrontational supportive approach, there is little evidence to suggest that formal MI works with older adults in regard to substance use. No studies among those that contributed to establishing MI as an evidenced-based practice included individuals older than 62 years. ${ }^{120}$ Some studies demonstrate efficacy of MI with older adults targeting other health behaviors, ${ }^{121}$ including smoking cessation ${ }^{122}$; some evidence suggests that it works in the context of case management to engage older adults in more formal treatment. ${ }^{19}$ Rigorous controlled trials of older adults and MI, or any other treatment, have yet to be conducted.

\section{Pharmacology}

A growing number of pharmacologic treatments can be used for SUD. Most of the research to date with older adults has been done on medications treating smoking cessation and alcohol use. Disulfiram, acamprosate, and naltrexone are medications approved by the Food and Drug Administration that are used to treat SUD; other medications, such as varenicline, are just emerging. Medication options for older adults are more limited than those in the general population, as evidence is lacking still about the efficacy and safety for some of these medications for an older population. Disulfiram is an aversive agent that increases the ill effects of alcohol ingestion by increasing acetaldehyde levels. ${ }^{123}$ Although it has been 
used with adults older than 50 years with some benefit, ${ }^{124}$ it has limitations. Disulfiram is only useful with strict adherence to the medication. There is also evidence that it places extra strain on the cardiovascular system within older adults and, thus, may be contraindicated. ${ }^{123}$

Acamprosate is an NMDA and GABA receptor modulator used to reduce craving and the pleasant effects of alcohol. ${ }^{123,125}$ No trials have been conducted to examine the efficacy of acamprosate for individuals aged 65 years and older. Because of the few reports of adverse effects across populations, it is considered relatively safe among older adults. ${ }^{126}$ In younger adults, 2 to $3 \mathrm{~g}$ of acamprosate is the recommended dose ${ }^{123}$; it has been tested in trials of 16 weeks ${ }^{127}$ to 1 year in length. ${ }^{128}$

Naltrexone is the most well-studied medication used for SUD treatment among older adults, ${ }^{112}$ and it has demonstrated some effectiveness with this population. Naltrexone is an opioid receptor antagonist thought to reduce craving and the pleasurable or stimulating effects of alcohol by blocking alcohol-induced dopamine release in the brain. ${ }^{123}$ It can be taken daily or as needed, although only daily treatment of naltrexone has been tested with older adults. The standard dose of naltrexone is $50 \mathrm{mg}$, but some studies have investigated its effects at larger doses (eg, $100 \mathrm{mg}$ ). The major limitation of naltrexone in an older-adult population, many of whom have chronic pain, is that it blocks the effect of opiate-based pain medications. It can also potentiate preexisting major depressive disorder symptoms. Patients with histories of comorbid depression should be closely monitored.

Two randomized controlled trials examined the impact of naltrexone versus placebo on older adults. ${ }^{129,130}$ In one study, 44 male veterans aged 50 years and older were randomly assigned to $50 \mathrm{mg} / \mathrm{d}$ of naltrexone or placebo and followed for 12 weeks. ${ }^{129}$ In addition to the medication, each participant also received weekly group therapy and case management. There were no significant differences between medication conditions on abstinence or relapse rates; however, among those individuals exposed to alcohol, older adults on naltrexone were significantly less likely to relapse than those on placebo. In a study of 183 adults, ${ }^{130}$ two-thirds of the subjects were randomly assigned to receive $100 \mathrm{mg}$ of naltrexone and one-third to placebo during 3 months of treatment. All participants received a medication management intervention with qualities similar to age-specific treatments, such as a nonconfrontational style. ${ }^{131}$ In a post hoc analysis, participants were divided into 2 age groups: 21 to 54 year olds and those 55 years old and older. ${ }^{130}$ Older adults demonstrated significantly greater rates of treatment engagement and medication adherence than the younger adults; however, only a trend level difference was found in medication effects between older and younger adults. Small sample sizes of older adults may have impeded the ability to detect significant main effects in both studies.

Varenicline is a nicotinic agonist that is a now widely used to aid smoking cessation. ${ }^{132,133}$ It has also recently been applied to alcohol dependence in a similar fashion as naltrexone. ${ }^{134}$ Although there are relatively few studies on varenicline with alcohol, existing studies demonstrate a reduction in drinking overall ${ }^{135}$ or a reduction in heavy drinking ${ }^{134}$ among a general population. No research yet exists on its effect with older adults. 


\section{Case Management}

Case and care management models, which are offered in primary care settings or community-based agencies, take advantage of nontraditional settings to engage older adults in reducing their use and/or connecting them to treatments. ${ }^{44}$ These interventions offer several advantages to an older-adult population. First, they provide a comprehensive approach by addressing the complexity of medical and psychiatric comorbidities common in this population ${ }^{16,90}$ while also connecting isolated older adults to needed community resources. Another advantage of these interventions is that substance use interventions are embedded in a broad approach to addressing health, lessening stigma, and also working toward a likely common goal among older adults: overall better health. ${ }^{16}$ Program evaluations of this model support the notion that case management is an important tool in working with this population. ${ }^{136-140}$ Case management models may be particularly effective at engaging and maintaining older at-risk drinkers in treatment. ${ }^{138}$

\section{Types of Care Available in the Formal Treatment System}

As with younger populations, formal substance abuse treatment of older adults is provided on a continuum of intensity depending on problem severity, ranging from detoxification to outpatient treatment or aftercare. ${ }^{44}$ All treatment plans should be individualized and flexible according to the specific needs of the client. Because of the unique issues facing older adults, both individual and group treatments are recommended. Although group treatment can reduce isolation and shame related to substance use and is often the preferred method of providing substance abuse treatment, the lack of elder-specific treatment available in the community ${ }^{113}$ may actually enhance feelings of isolation and shame in a group context. Older adults may not easily relate to or feel uncomfortable discussing their problems with younger persons. Individual therapy provides a private and confidential forum for older adults to explore their unique issues, without these same risks.

Two psychosocial and psychotherapeutic approaches have been explored specifically in the context of older adults: supportive therapy models (STM) ${ }^{141}$ and cognitive-behavioral therapy (CBT). ${ }^{92-94,142,143}$ STM represent traditional treatment with age-specific modifications. Twenty-five years ago, STM approaches arose out of a concern about whether older adults could effectively engage in standard treatment. ${ }^{141}$ It was observed that confrontational approaches were ill suited and disrespectful to older adults and that the unique issues faced by older individuals, including health conditions, depression comorbidity, and social isolation, went unaddressed. ${ }^{16}$ Although it is now widely accepted that confronting denial in any individual about their drug or alcohol use is ineffective in helping individuals modify their behavior to be more healthy, ${ }^{118}$ STM were designed to focus on developing a culture of support and successful coping for older-adult substance abusers; supportive therapies concentrate on building social support, improving self-esteem, and taking a global approach to treatment planning through addressing multiple biopsychosocial arenas in the client's life. ${ }^{44}$ Although there has been relatively little research on age-specific treatments incorporating these techniques, there is at least some evidence that older adults demonstrate better outcomes in these settings than in nonadapted settings. ${ }^{112,141,144}$ 
CBT focuses on identifying and altering sequences of thinking, feeling, and behaving that lead to problem drinking or drug use. ${ }^{145} \mathrm{CBT}$ can be delivered individually or in group settings, and there is strong evidence for positive outcomes across populations and age groups. ${ }^{146}$ There is also evidence for the effectiveness of CBT with older adults, ${ }^{92-94,142,143}$ and the Substance Abuse and Mental Health Services Association published a CBT treatment manual specific to substance-using older adults. ${ }^{16}$ The highly structured, didactic approach taken in CBT may be particularly helpful to older adults because of the tendency to present with memory difficulties. ${ }^{16}$ Finally, CBT interventions have outperformed nicotine replacement therapies among older adults participating in a smoking cessation program. ${ }^{27}$

\section{SELF-HELP GROUPS}

Alcoholics or Narcotics Anonymous and their related groups can be useful to older adults in reducing isolation, shame, and stigma, ${ }^{44}$ though there have been no systematic studies on the effects of these groups on older adults. ${ }^{147}$ Older adults may encounter the same barriers to participation in self-help groups as they do with formal treatment: primarily stigma and shame of needing to attend to these issues in late life in the presence of a younger generation. Older generations of older adults whose primary substance is alcohol may also experience more discomfort in attending meetings that include younger polysubstance users, ${ }^{147}$ though this may be less of an issue for baby boomers. Furthermore, specific meetings may be more or less suited to older adults given the variation in the pace of meetings and the general focus of the group. Some experts have recommended traditional self-help groups be modified for older adults, such as slowing the pace of the meeting to reflect cognitive changes in aging and devoting attention to handling losses and extending social support. ${ }^{148}$ Being aware of elder-friendly meetings in the geographic area may be helpful for intervening with older adults. When referring to self-help groups, it is also important to encourage older adults to try more than one meeting before deciding whether it is a good fit because each meeting has a unique tone and feel.

\section{SUMMARY}

The myth that older adults do not use substances and/or do not use substances problematically has been dispelled. Older-adult substance users may not present with the same symptoms as their younger counterparts and, therefore, may be more difficult to identify. Treatment options remain generally limited, as few programs or health care settings offer tailored interventions for older adults. Health care professionals need to continue to do as thorough of assessments as possible and enlist the help of formal measures, Web-based assessment, and build in the questions outlined earlier as routine. As the baby boom generation ages, the health care system will be challenged to provide culturally competent services to this group, as they are a unique generation of older adults. Knowledge about older-adult substance use and the issues that contribute to late onset or maintained addiction in late life will need to be continually updated as we learn how and why this generation of adults uses substances. Furthermore, the advancement and development of interventions that may be more useful for, effective for, and desired by this incoming generation of older 
adults than previous generation, such as mobile interventions, will be crucial to alleviating the projected pressures on the health care system.

\section{REFERENCES}

1. U.S. Census Bureau. [Accessed April 11, 2011] Population profile of the United States. 2010. Available at: http://www.census.gov/population/www/pop-profile/natproj.html.

2. World Health Organization. [Accessed May 13, 2013] Life expectancy: Life expectancy data by country. 2012. Available at: http://apps.who.int/gho/data/node.main.688?lang=en.

3. Institute of Medicine. The mental health and substance use workforce for older adults: in whose hands?. Washington, DC: The National Academies Press; 2012.

4. Cummings SM, Bride B, Rawlins-Shaw AM. Alcohol abuse treatment for older adults: a review of recent empirical research. J Evid Based Soc Work. 2006; 3(1):79-99.

5. Substance Abuse and Mental Health Services Administration. Rockville (MD): Substance Abuse and Mental Health Services Administration; 2013. Results from the 2012 National Survey on Drug Use and Health: summary of national findings. NSDUH Series H-46, HHS Publication No. (SMA) 13-4795.

6. Arndt S, Clayton R, Schultz S. Trends in substance abuse treatment 1998-2008: increasing older adult first time admissions for illicit drugs. Am J Geriatr Psychiatry. 2011; 19:704-711. [PubMed: 21785290]

7. Atkinson RM. Aging and alcohol use disorders: diagnostic issues in the elderly. Int Psychogeriatr. 1990; 2(1):55-72. [PubMed: 2101298]

8. Atkinson, RM.; Ganzini, L. Substance abuse. In: Coffey, CE.; Cummings, JL., editors. Textbook of geriatric neuropsychiatry. Washington, DC: American Psychiatric Press; 1994. p. 297-321.

9. Ekerdt DJ, De Labry LO, Glynn RJ, et al. Change in drinking behaviors with retirement: findings from the Normative Aging Study. J Stud Alcohol. 1989; 50(4):347-353. [PubMed: 2787876]

10. Moore AA, Karno MP, Grella CE, et al. Alcohol, tobacco, and nonmedical drug use in older U.S. adults: data from the 2001/02 National Epidemiologic Survey of Alcohol and Related Conditions. J Am Geriatr Soc. 2009; 57(12):2275-2281. [PubMed: 19874409]

11. Han B, Gfroerer JC, Colliver JD, et al. Substance use disorder among older adults in the United States in 2020. Addiction. 2009; 104:88-96. [PubMed: 19133892]

12. Institute of Medicine. Retooling for an aging America: building the health care workforce. Washington, DC: The National Academies Press; 2008.

13. Jeste DV, Alexopoulos GS, Bartels SJ, et al. Consensus statement on the upcoming crisis in geriatric mental health: research agenda for the next two decades. Arch Gen Psychiatry. 1999; 56(9):848-853. [PubMed: 12884891]

14. Moos RH, Schutte KK, Brennan PL, et al. Older adults' alcohol consumption and late-life drinking problems: a 20-year perspective. Addiction. 2009; 104:1293-1302. [PubMed: 19438836]

15. Kirchner J, Zubritsky C, Cody M, et al. Alcohol consumption among older adults in primary care. J Gen Intern Med. 2007; 22:92-97. [PubMed: 17351846]

16. Center for Substance Abuse Treatment. Substance abuse among older adults: Treatment Improvement Protocol (TIP) Series 26. Rockville (MD): Substance Abuse and Mental Health Services Administration; 1998.

17. Moore AA, Gould R, Reuben DB, et al. Longitudinal patterns and predictors of alcohol consumption in the United States. Am J Public Health. 2005; 95(3):458-465. [PubMed: 15727977]

18. Grant BF, Dawson DA, Stinson FS, et al. The 12-month prevalence and trends in DSM-IV alcohol abuse and dependence: United States, 1991-1992 and 2001-2002. Drug Alcohol Depend. 2004; 74:223-234. [PubMed: 15194200]

19. Conigliaro J, Kraemer KL, McNeil M. Screening and identification of older adults with alcohol problems in primary care. J Geriatr Psychiatry Neurol. 2000; 13:106-114. [PubMed: 11001132] 
20. Blazer DG, Wu L. The epidemiology of at risk and binge drinking among middle-aged and elderly community adults: national survey on drug use and health. Am J Psychiatry. 2009; 166:11621169. [PubMed: 19687131]

21. Holroyd S, Duryee JJ. Substance use disorders in a geriatric psychiatry outpatient clinic: prevalence and epidemiologic characteristics. J Nerv Ment Dis. 1997; 185:627-632. [PubMed: 9345253]

22. Kennedy GJ, Efremova I, Frazier A, et al. The emerging problems of alcohol and substance abuse in late life. J Soc Distress Homel. 1999; 8(4):227-239.

23. Merrick EL, Horgan CM, Hodgkin D, et al. Unhealthy drinking patterns in older adults: prevalence and associated characteristics. J Am Geriatr Soc. 2008; 56:214-223. [PubMed: 18086124]

24. Blazer DG, $\mathrm{Wu} \mathrm{L}$. The epidemiology of substance use and disorders among middle aged and elderly community adults: national survey on drug use and health. Am J Geriatr Psychiatry. 2009; 17:237-245. [PubMed: 19454850]

25. Moore AA, Endo JO, Carter MK. Is there a functional relationship between excessive drinking and functional impairment in older persons? J Am Geriatr Soc. 2003; 51:44-49. [PubMed: 12534844]

26. Sorocco KH, Ferrell SW. Alcohol use among older adults. J Genet Psychol. 2006; 133(4):453-467.

27. Hall SM, Humfleet GL, Munoz RF, et al. Extended treatment of older cigarette smokers. Addiction. 2009; 104:1043-1052. [PubMed: 19392908]

28. Rimer B, Orleans CT, Fleisher L, et al. Does tailoring matter? The impact of a tailored guide on ratings and short-term smoking-related outcomes for older adult smokers. Health Educ Res. 1994; 9:69-84. [PubMed: 10146734]

29. Blazer DG, Wu LT. Patterns of tobacco use and tobacco-related psychiatric morbidity and substance use among middle-aged and older adults in the United States. Aging Ment Health. 2012; 16:296-304. [PubMed: 22292514]

30. Degenhardt L, Dierker L, Chiu WT, et al. Evaluating the drug use "gateway" theory using crossnational data: consistency and associations of the order of initiation of drug use among participants in the WHO World Mental Health Surveys. Drug Alcohol Depend. 2010; 108(1-2):84-97. [PubMed: 20060657]

31. Wu LT, Blazer DG. Illicit and nonmedical drug use among older adults: a review. J Aging Health. 2011; 23:481-504. [PubMed: 21084724]

32. Blazer DG, Wu L. Nonprescription use of pain relievers by middle-aged and elderly communityliving adults: national survey on drug use and health. J Am Geriatr Soc. 2009; 57:1252-1257. [PubMed: 19486199]

33. Oslin, DW.; Mavandadi, S. Alcohol and drug problems. In: Blazer, DG.; Steffens, DC., editors. Textbook of geriatric psychiatry. Arlington (VA): American Psychiatric Publishing; 2009. p. 1-17.

34. Golden AG, Preston RA, Barnett SD, et al. Inappropriate medication prescribing in homebound older adults. J Am Geriatr Soc. 1999; 47(8):948-953. [PubMed: 10443855]

35. Qato DM, Alexander GC, Conti RM, et al. Use of prescription and over-the-counter medications and dietary supplements among older adults in the United States. JAMA. 2008; 300(24):28672878. [PubMed: 19109115]

36. Simoni-Wastila L, Yang HK. Psychoactive drug abuse in older adults. Am J Geriatr Pharmacother. 2006; 4(4):380-394. [PubMed: 17296542]

37. Achildi O, Leong SH, Maust DT, et al. Patterns of newly-prescribed benzodiazepines in late life. Am J Geriatr Psychiatry. 2013; 21 Suppl 1(3):S90-S91.

38. Llorente M, David D, Golden AG, et al. Defining patterns of benzodiazepine use in older adults. J Geriatr Psychiatry Neurol. 2000; 13:150-160. [PubMed: 11001138]

39. Bartels SJ, Coakley EH, Zubritsky C, et al. Improving access to geriatric mental health services: a randomized trial comparing treatment engagement with integrated versus enhanced referral care for depression, anxiety, and at-risk alcohol use. Am J Psychiatry. 2004; 161:1455-1462. [PubMed: 15285973]

40. Oslin DW. Alcohol use in late life: disability and comorbidity. J Geriatr Psychiatry Neurol. 2000; 13:134-140. [PubMed: 11001136] 
41. Gilbertson R, Ceballos NA, Prather R, et al. Effects of acute alcohol consumption in older and younger adults: perceived impairment versus psychomotor performance. J Stud Alcohol Drugs. 2009; 70(2):242-252. [PubMed: 19261236]

42. Blow FC, Barry KL. Older patients with at-risk and problem drinking patterns: new developments in brief interventions. J Geriatr Psychiatry Neurol. 2000; 13:115-123. [PubMed: 11001133]

43. Sklar AR, Gilbertson R, Boissoneault J, et al. Differential effects of moderate alcohol consumption on performance among older and younger adults. Alcohol Clin Exp Res. 2012; 36(12):2150-2156. [PubMed: 22591190]

44. Sacco, P.; Kuerbis, A. Older adults. In: Vaughn, MG.; Perron, BE., editors. Social work practice in the addictions. New York: Springer; 2013. p. 213-229.

45. Thun MJ, Peto R, Lopez AD, et al. Alcohol consumption and mortality among middle-aged and elderly U.S. adults. N Engl J Med. 1997; 337(24):1705-1714. [PubMed: 9392695]

46. Mukamal KJ, Kuller LH, Fitzpatrick AL, et al. Prospective study of alcohol consumption and risk of dementia in older adults. JAMA. 2003; 289(11):1405-1413. [PubMed: 12636463]

47. Chen LY, Hardy CL. Alcohol consumption and health status in older adults. J Aging Health. 2009; 21(6):824-847. [PubMed: 19581424]

48. Kaplan MS, Huguet N, Feeny D, et al. Alcohol use patterns and trajectories of health-related quality of life in middle-aged and older adults: a 14-year population-based study. J Stud Alcohol Drugs. 2012; 73:581-590. [PubMed: 22630796]

49. Maraldi C, Harris TB, Newman AB, et al. Moderate alcohol intake and risk of functional decline: the Health, Aging, and Body Composition study. J Am Geriatr Soc. 2009; 57(10):1767-1775. [PubMed: 19737328]

50. Saitz R. Unhealthy alcohol use. N Engl J Med. 2005; 352(6):596-607. [PubMed: 15703424]

51. Moore AA, Whiteman EJ, Ward KT. Risks of combined alcohol/medication use in older adults. Am J Geriatr Pharmacother. 2007; 5:64-74. [PubMed: 17608249]

52. Doweiko, HE. Concepts of chemical dependency. 6th edition. Pacific Grove (CA): Brooks/Cole; 2006.

53. National Institute on Drug Abuse. Marijuana abuse. Bethesda (MD): National Institute on Drug Abuse; 2012.

54. LaCroix AZ, Guralnik JM, Berkman LF, et al. Maintaining mobility in late life. II. Smoking, alcohol consumption, physical activity and body mass index. Am J Epidemiol. 1993; 137(8):858869. [PubMed: 8484377]

55. LaCroix AZ, Omenn GS. Older adults and smoking. Clin Geriatr Med. 1992; 8(1):69-87. [PubMed: 1576581]

56. Stewart D, Oslin DW. Recognition and treatment of late-life addictions in medical settings. Journal of Clinical Geropsychology. 2001; 7(2):145-158.

57. Platt A, Sloan FA, Costanzo P. Alcohol-consumption trajectories and associated characteristics among adults older than age 50. J Stud Alcohol Drugs. 2010; 71:169-179. [PubMed: 20230713]

58. Moos RH, Brennan PL, Schutte KK, et al. Older adults' health and late-life drinking patterns: a 20year perspective. Aging Ment Health. 2010; 14(1):33-43. [PubMed: 20155519]

59. Collins PM, Kayser K, Platt S. Conjoint marital therapy: a practitioner's approach to single-system evaluation. Fam Soc. 1994; 75:131-141.

60. Perriera KM, Sloan FA. Life events and alcohol consumption among mature adults: a longitudinal analysis. J Stud Alcohol. 2001; 62:501-508. [PubMed: 11513228]

61. Sacco P, Bucholz KK, Spitznagel EL. Alcohol use among older adults in the National Epidemiologic Survey on Alcohol and Related Conditions. J Stud Alcohol Drugs. 2009; 70(6): 829-838. [PubMed: 19895759]

62. Balsa AI, Homer JF, Fleming MF, et al. Alcohol consumption and health among elders. Gerontologist. 2008; 48(5):622-636. [PubMed: 18981279]

63. Speer DC, Bates K. Comorbid mental and substance disorders among older psychiatric patients. J Am Geriatr Soc. 1992; 40:886-890. [PubMed: 1512383]

64. Oslin DW. Treatment of late-life depression complicated by alcohol dependence. Am J Geriatr Psychiatry. 2005; 13(6):491-500. [PubMed: 15956269] 
65. Blow FC, Cook CL, Booth BM, et al. Age-related psychiatric comorbidities and level of functioning in alcoholic veterans seeking outpatient treatment. Hosp Community Psychiatry. 1992; 43:990-995. [PubMed: 1328023]

66. Lin JC, Karno MP, Grella CE, et al. Psychiatric correlates of alcohol and tobacco use disorders in U.S. adults aged 65 years and older: results from the 2001-2002 National Epidemiologic Survey of Alcohol and Related Conditions. Am J Geriatr Pharmacology. 2013 Epub ahead of print.

67. Wu LT, Blazer DG. Substance use disorders and psychiatric comorbidity in mid and later life: a review. Int J Epidemiol. 2014; 43(2):304-317. [PubMed: 24163278]

68. Adlaf EM, Smart RG. Alcohol use, drug use, and well-being in older adults in Toronto. Int J Addict. 1995; 30(13-14):1985-2016. [PubMed: 8751326]

69. Dar K. Alcohol use disorders in elderly people: fact or fiction? Adv Psychiatr Treat. 2006; 12:173181.

70. Thomas VS, Rockwood KJ. Alcohol abuse, cognitive impairment, and mortality among older people. J Am Geriatr Soc. 2001; 49:415-420. [PubMed: 11347785]

71. Moore AA, Giuli L, Gould R, et al. Alcohol use, comorbidity, and mortality. J Am Geriatr Soc. 2006; 54:757-762. [PubMed: 16696740]

72. Moos RH, Schutte KK, Brennan PL, et al. Late-life and life history predictors of older adults' high risk consumption and drinking problems. Drug Alcohol Depend. 2010; 108:13-20. [PubMed: 19969428]

73. Adams WL. Alcohol use in the retirement communities. J Am Geriatr Soc. 1996; 44:1082-1085. [PubMed: 8790236]

74. Brennan PL, Schutte KK, Moos RH. Reciprocal relations between stressors and drinking behavior: a three-wave panel study of late middle-aged and older women and men. Addiction. 1999; 94(5): 737-749. [PubMed: 10563039]

75. Center for Substance Abuse Treatment. Substance abuse relapse prevention for older adults: a group treatment approach. Rockville (MD): Substance Abuse and Mental Health Services Administration; 2005.

76. Myers JE, Harper MC. Evidence-based effective practices with older adults. J Couns Dev. 2004; 82:207-218.

77. Laidlaw K, Pachana NA. Aging, mental health, and demographic change: challenges for psychotherapists. PrPsychol Res Pract. 2009; 40(6):601-608.

78. Kuerbis A, Sacco P. The impact of retirement on the drinking patterns of older adults: a review. Addict Behav. 2012; 37:587-595. [PubMed: 22365490]

79. Bacharach SB, Bamberger PA, Cohen A, et al. Retirement, social support, and drinking behavior: a cohort analysis of males with a baseline history of problem drinking. J Drug Issues. 2007; 37(3): 525-548.

80. Stergiopoulos V, Herrmann N. Old and homeless: a review and survey of older adults who use shelters in an urban setting. Can J Psychiatry. 2003; 48(6):374-380. [PubMed: 12894611]

81. Joseph CL. Alcohol and drug misuse in the nursing home. Int J Addict. 1995; 30(13-14):19531984. [PubMed: 8751325]

82. Joseph CL, Atkinson RM, Ganzini L. Problem drinking among residents of a VA nursing home. Int J Geriatr Psychiatry. 1995; 10(3):243-248.

83. Klein WC, Jess C. One last pleasure? Alcohol use among elderly people in nursing homes. Health Soc Work. 2002; 27(3):193-203. [PubMed: 12230044]

84. American Psychiatric Association. Diagnostic and statistical manual of mental disorders. 4th edition. Washington, DC: Author; 2000.

85. American Psychiatric Association. Diagnostic and statistical manual of mental disorders. 5th edition. Arlington (VA): American Psychiatric Publishing; 2013.

86. Kuerbis A, Hagman BT, Sacco P. Functioning of alcohol use disorders criteria among middle-aged and older adults: implications for DSM-5. Subst Use Misuse. 2013; 48(4):309-322. [PubMed: 23373632]

87. Moody, HR. Aging: concepts and controversies. 5th edition. Thousand Oaks (CA): Pine Forge; 2006. 
88. Duru OK, Xu H, Tseng CH, et al. Correlates of alcohol-related discussions between older adults and their physicians. J Am Geriatr Soc. 2010; 58(12):2369-2374. [PubMed: 21087224]

89. D'Amico EJ, Paddock SM, Burnam A, et al. Identification of and guidance for problem drinking by general medical providers: results from a national survey. Med Care. 2005; 43(3):229-236. [PubMed: 15725979]

90. Barry, KL.; Oslin, DW.; Blow, FC. Alcohol problems in older adults. New York: Springer Publishing Company; 2001.

91. Rodin J. Aging and health: effects of the sense of control. Science. 1986; 233:1271-1276. [PubMed: 3749877]

92. Dupree LW, Broskowski H, Schonfeld L. The Gerontology Alcohol Project: a behavioral treatment program for elderly alcohol abusers. Gerontologist. 1984; 24:510-516. [PubMed: 6500273]

93. Schonfeld L, Dupree LW. Treatment approaches for older problem drinkers. Int J Addict. 1995; 30(13-14):1819-1842. [PubMed: 8751320]

94. Schonfeld L, Dupree LW, Dickson-Fuhrman E, et al. Cognitive-behavioral treatment of older veterans with substance abuse problems. J Geriatr Psychiatry Neurol. 2000; 13:124-128. [PubMed: 11001134]

95. Lemke S, Moos RH. Prognoses of older patients in mixed-age alcoholism treatment programs. J Subst Abuse Treat. 2002; 22:33-34. [PubMed: 11849905]

96. Gecas V. The social psychology of self-efficacy. Am Rev Sociol. 1989; 15:291-316.

97. Brown RL, Rounds LA. Conjoint screening questionnaires for alcohol and other drug abuse. Wis Med J. 1995; 94(3):135-140. [PubMed: 7778330]

98. Buchsbaum DG, Buchanan R, Welsh J, et al. Screening for drinking disorders in the elderly using the CAGE questionnaire. J Am Geriatr Soc. 1992; 40:662-665. [PubMed: 1607581]

99. Adams W, Barry KL, Fleming MF. Screening for problem drinking in older primary care patients. JAMA. 1996; 276:1964-1967. [PubMed: 8971065]

100. O'Connell H, Chin AV, Hamilton F, et al. A systematic review of the utility of self-report alcohol screening instruments in the elderly. Int J Geriatr Psychiatry. 2004; 19:1074-1086. [PubMed: 15481069]

101. Blow FC, Brower KJ, Schulenberg JE, et al. The Michigan Alcohol Screening Test: Geriatric Version (MAST-G): a new elderly specific screening instrument. Alcohol Clin Exp Res. 1992; 16:172. [PubMed: 1590537]

102. Barry, KL.; Blow, FC. Screening, assessing and intervening for alcohol and medication misuse in older adults. In: Lichtenberg, PA., editor. Handbook of assessment in clinical gerontology. Burlington (MA): Elsevier; 2010. p. 307-330.

103. Babor, TF.; Higgins-Biddle, JC.; Saunders, JB., et al. The Alcohol Use Disorders Identification Test (AUDIT): guidelines for use in primary care. 2nd edition. Geneva (Switzerland): Department of Mental Health and Substance Dependence, World Health Organization; 2001.

104. Beullens J, Aertgeerts B. Screening for alcohol abuse and dependence in older people using DSM criteria: a review. Aging Ment Health. 2004; 8(1):76-82. [PubMed: 14690871]

105. Piccinelli M, Tessari E, Bortolomasi M, et al. Efficacy of the alcohol use disorders identification test as a screening tool for hazardous alcohol intake and related disorders in primary care: a validity study. BMJ. 1997; 314(8):420-424. [PubMed: 9040389]

106. Humeniuk, R.; Henry-Edwards, S.; Ali, R., et al. Geneva (Switzerland): World Health Organization; 2010. The alcohol, smoking, and substance involvement screening test (ASSIST).

107. Moore AA, Beck JC, Babor TF, et al. Beyond alcoholism: identifying older, at-risk drinkers in primary care. J Stud Alcohol. 2002; 63(3):316-324. [PubMed: 12086132]

108. Fink A, Morton SC, Beck JC, et al. The Alcohol-Related Problems Survey: identifying hazardous and harmful drinking in older primary care patients. J Am Geriatr Soc. 2002; 50:1717-1722. [PubMed: 12366628]

109. Barnes AJ, Moore AA, Xu H, et al. Prevalence and correlates of at-risk drinking among older adults: the project SHARE study. J Gen Intern Med. 2010; 25(8):840-846. [PubMed: 20396975] 
110. Moore AA, Blow FC, Hoffing M, et al. Primary care-based intervention to reduce at-risk drinking in older adults: a randomized controlled trial. Addiction. 2011; 106(1):111-120. [PubMed: 21143686]

111. Brennan PL, Nichol AC, Moos RH. Older and younger patients with substance use disorders: outpatient mental health service use and functioning over a 12-month interval. Psychol Addict Behav. 2003; 17(1):42-48. [PubMed: 12665080]

112. Kuerbis AN, Sacco P. A review of existing treatments for substance abuse among the elderly and recommendations for future directions. Subst Abuse. 2013; 7:13-37. [PubMed: 23471422]

113. Schultz SK, Arndt S, Liesveld J. Locations of facilities with special programs for older substance abuse clients in the US. Int J Geriatr Psychiatry. 2003; 18(9):839-843. [PubMed: 12949852]

114. Fortney JC, Booth BM, Blow FC, et al. The effects of travel barriers and age on utilization of alcoholism treatment aftercare. Am J Drug Alcohol Abuse. 1995; 21(3):391-407. [PubMed: 7484987]

115. Schonfeld L, King-Kallimanis BL, Duchene DM, et al. Screening and brief intervention for substance misuse among older adults: the Florida BRITE project. Am J Public Health. 2010; 100(1):108-114. [PubMed: 19443821]

116. Fleming MF, Manwell LB, Barry KL, et al. Brief physician advice for alcohol problems in older adults: a randomized community-based trial. J Fam Pract. 1999; 48(5):378-384. [PubMed: 10334615]

117. Fink A, Elliot MN, Tsai M, et al. An evaluation of an intervention to assist primary care physicians in screening and educating older patients who use alcohol. J Am Geriatr Soc. 2005; 53:1937-1943. [PubMed: 16274375]

118. Miller, WR.; Rollnick, S. Motivational interviewing: preparing people for change. 2 nd edition. New York: The Guilford Press; 2002.

119. Miller, WR.; Zweben, A.; DiClemente, CC., et al. Motivational enhancement therapy manual: a clinical research guide for therapists treating individuals with alcohol abuse and dependence. Rockville (MD): National Institute on Alcohol Abuse and Alcoholism; 1992.

120. Hettema J, Steele J, Miller WR. Motivational interviewing. Annu Rev Clin Psychol. 2005; 1:91111. [PubMed: 17716083]

121. Cummings SM, Cooper RL, Cassie KM. Motivational interviewing to affect behavioral change in older adults. Res Soc Work Pract. 2009; 19(2):195-204.

122. Hokanson JM, Anderson RL, Hennrikus DJ, et al. Integrated tobacco cessation counseling in a diabetes self-management training program: a randomized trial of diabetes and reduction of tobacco. Diabetes Educ. 2006; 32:562-570. [PubMed: 16873594]

123. Barrick C, Connors GD. Relapse prevention and maintaining abstinence in older adults with alcohol-use disorders. Drugs Aging. 2002; 19(8):583-594. [PubMed: 12207552]

124. Garbutt JC, West SL, Carey TS, et al. Pharmacological treatment of alcohol dependence: a review of the evidence. JAMA. 1999; 281(14):1318-1325. [PubMed: 10208148]

125. Tempesta E, Janiri L, Bignamini A, et al. Acamprosate and relapse prevention in the treatment of alcohol dependence: a placebo controlled trial. Pharmacopsychiatry. 2000; 29:27-29.

126. U.S. National Library of Congress. [Accessed May 4, 2013] DailyMed. 2013. Available at: http:// dailymed.nlm.nih.gov/dailymed/about.cfm

127. Anton R, O'Malley SS, Ciraulo DA, et al. Combined pharmacotherapies and behavioral interventions for alcohol dependence. The COMBINE study: a randomized controlled trial. JAMA. 2006; 295:2003-2017. [PubMed: 16670409]

128. Rubio G, Jimenez-Arriero MA, Ponce G, et al. Naltrexone versus acamprosate: one year follow up of alcohol dependence treatment. Alcohol Alcohol. 2001; 36(5):419-425. [PubMed: 11524308]

129. Oslin DW, Liberto JG, O'Brien J, et al. Naltrexone as an adjunctive treatment for older patients with alcohol dependence. Am J Geriatr Psychiatry. 1997; 5(4):324-332. [PubMed: 9363289]

130. Oslin DW, Pettinati H, Volpicelli JR. Alcoholism treatment adherence: older age predicts better adherence and drinking outcomes. Am J Geriatr Psychiatry. 2002; 10(6):740-747. [PubMed: 12427583] 
131. Volpicelli, JR.; Pettinati, HM.; McLellan, AT., et al. Combining medication and psychosocial treatment for addiction: the BRENDA approach. New York (NY): Guilford Press; 2001.

132. Keating GM, Lyseng-Williamson KA. Varenicline: a pharmacoeconomic review of its use as an aid to smoking cessation. Pharmacoeconomics. 2010; 28(3):231-254. [PubMed: 20108995]

133. Garrison GD, Dugan SE. Varenicline: a first-line treatment option for smoking cessation. Clin Ther. 2009; 31(3):463-491. [PubMed: 19393839]

134. Plebani JG, Lynch KG, Rennert L, et al. Results from a pilot clinical trial of varenicline for the treatment of alcohol dependence. Drug Alcohol Depend. 2013; 133(2):754-758. [PubMed: 23916324]

135. Litten RZ, Ryan ML, Fertig JB, et al. A double-blind, placebo-controlled trial assessing the efficacy of varenicline tartrate for alcohol dependence. J Addict Med. 2013; 7(4):277-286. [PubMed: 23728065]

136. Lee HS, Mericle AA, Ayalon L, et al. Harm reduction among at-risk elderly drinkers: a sitespecific analysis from the multi-site primary care research in substance abuse and mental health for elderly (PRISM-E) study. Int J Geriatr Psychiatry. 2009; 24(1):54-60. [PubMed: 18613283]

137. Levkoff SE, Chen H, Coakley E, et al. Design and sample characteristics of the PRISM-E multisite randomized trial to improve behavioral health care for the elderly. J Aging Health. 2004; 16:3-27. [PubMed: 14979308]

138. Oslin DW, Grantham S, Coakley E, et al. PRISM-E: comparison of integrated care and enhanced specialty referral in managing at-risk alcohol use. Psychiatr Serv. 2006; 57(7):954-958. [PubMed: 16816279]

139. Zanjani F, Mavandadi S, TenHave T, et al. Longitudinal course of substance treatment benefits in older male veteran at-risk drinkers. J Gerontol A Biol Sci Med Sci. 2008; 63A(1):98-106. [PubMed: 18245767]

140. D’Agostino CS, Barry KL, Blow FC, et al. Community interventions for older adults with comorbid substance use: the Geriatrics Addiction Program (GAP). J Dual Diagn. 2006; 2(3):3143.

141. Kofoed LL, Tolson RL, Atkinson RM, et al. Treatment compliance of older alcoholics: an elderspecific approach is superior to "mainstreaming". J Stud Alcohol. 1987; 48:47-51. [PubMed: 3821118]

142. Rice C, Longabaugh R, Beattie M, et al. Age group differences in response to treatment for problematic alcohol use. Addiction. 1993; 88:1369-1375. [PubMed: 8251874]

143. Schonfeld, L.; Dupree, LW. Age-specific cognitive behavioral and self-management treatment approaches. In: Gurnack, AM.; Atkinson, RM.; Osgood, NJ., editors. Treating alcohol and drug abuse in the elderly. New York: Springer Publishing Company; 2002. p. 109-130.

144. Kashner M, Rodell DE, Ogden SR, et al. Outcomes and costs of two VA inpatient treatment programs for older adult alcoholic patients. Hosp Community Psychiatry. 1992; 43:985-989. [PubMed: 1328022]

145. Rotgers, F. Cognitive-behavioral theories of substance abuse. In: Rotgers, F.; Morgenstern, J.; Walters, ST., editors. Treating substance abuse: theory and technique. 2nd edition. New York: The Guilford Press; 2003. p. 166-189.

146. Morgenstern J, McKay J. Rethinking the paradigms that inform behavioral treatment research for substance use disorders. Addiction. 2007; 102:1377-1389. [PubMed: 17610541]

147. Atkinson, RM.; Misra, S. Further strategies in the treatment of aging alcoholics. In: Gurnack, AM.; Atkinson, RM.; Osgood, NJ., editors. Treating alcohol and drug abuse in the elderly. New York: Springer; 2002. p. 131-151.

148. Schonfeld, L.; Dupree, LW. Treatment alternatives for older adults. In: Gurnack, AM., editor. Older adults' misuse of alcohol, medicine, and other drugs. New York: Springer; 1997. p. 113-131.

149. Barry KL, Blow FC, Oslin DW. Substance abuse in older adults: review and recommendations for education and practice in medical settings. Subst Abus. 2002; 23(Suppl 3):105-131. [PubMed: 23580990] 


\section{KEY POINTS}

- Although the current proportions of older adults with substance use disorders remain low compared with the general population, a growing proportion and number of older adults are at risk for hazardous drinking, prescription drug misuse, and illicit substance use and abuse.

- The identification of problematic substance use with older adults can be difficult because of overlapping symptoms with medical disorders that are common in older age.

- The assessment should include a respectful and nonstigmatizing approach along with direct questions about drinking, prescription medication, and illicit drug use.

- Several brief interventions centered on education about the harms of substance use have been shown to be effective with older adults.

- For older adults with more severe substance use problems, more intensive treatments geared toward a general population have been shown to be effective for older adults; however, treatments tailored for older adults have shown particular promise. 


\section{Box 1 Risk factors related to substance use in late life}

Physical risk factors

Male sex (for alcohol), female sex (for prescription drug)

Caucasian ethnicity

Chronic pain

Physical disabilities or reduced mobility

Transitions in care/living situations

Poor health status

Chronic physical illness/polymorbidity

Significant drug burden/polypharmacy

Psychiatric risk factors

Avoidance coping style

History of alcohol problems

Previous and/or concurrent SUD

Previous and/or concurrent psychiatric illness

Social risk factors

Affluence

Bereavement

Unexpected or forced retirement

Social isolation (living alone or with nonspousal others) 


\section{Box 2 Potential indicators of substance misuse and abuse}

Physical symptoms or potential indicators

Falls, bruises, and burns ${ }^{149}$

Poor hygiene ${ }^{149}$ or impaired self-care ${ }^{69}$

Headaches ${ }^{149}$

Incontinence ${ }^{149}$

Increased tolerance to alcohol or medications ${ }^{149}$ or unusual response to medications ${ }^{69}$

Poor nutrition ${ }^{149}$

Idiopathic seizures ${ }^{149}$

Dizziness ${ }^{149}$

Sensory deficits ${ }^{69}$

Blackouts ${ }^{69}$

Chronic pain

Cognitive symptoms or potential indicators

Disorientation ${ }^{149}$

Memory loss ${ }^{149}$

Recent difficulties in decision making ${ }^{149}$

Overall cognitive impairment ${ }^{69}$

Psychiatric symptoms or potential indicators 149

Sleep disturbances, problems, or insomnia

Anxiety

Depression

Excessive mood swings

Social symptoms or potential indicators

Family problems ${ }^{149}$

Financial problems ${ }^{149}$

Legal problems ${ }^{149}$

Social isolation ${ }^{149}$

Running out of medication early ${ }^{44}$

Borrowing medication from others ${ }^{44}$ 
Table 1

SUD (formerly substance abuse or dependence) criteria $^{a}$

\begin{tabular}{|c|c|}
\hline DSM-5 Criteria for SUD & Consideration for Older Adult \\
\hline $\begin{array}{l}\text { A substance is often taken in larger amounts or over a longer period than } \\
\text { was intended. }\end{array}$ & $\begin{array}{l}\text { Cognitive impairment can prevent adequate self-monitoring. } \\
\text { Substances themselves may more greatly impair cognition } \\
\text { among older adults than younger adults. }\end{array}$ \\
\hline $\begin{array}{l}\text { There is a persistent desire or unsuccessful efforts to cut down or control } \\
\text { substance use. }\end{array}$ & It is the same as the general adult population. \\
\hline $\begin{array}{l}\text { A great deal of time is spent in activities necessary to obtain the substance, } \\
\text { use the substance, or recover from its effects. }\end{array}$ & $\begin{array}{l}\text { Consequences from substance use can occur from using } \\
\text { relatively small amounts. }\end{array}$ \\
\hline There is craving or a strong desire to use the substance. & $\begin{array}{l}\text { It is the same as the general adult population. Older adults with } \\
\text { entrenched habits may not recognize cravings in the same way as } \\
\text { the general adult population. }\end{array}$ \\
\hline $\begin{array}{l}\text { There is recurrent substance use resulting in a failure to fulfill major role } \\
\text { obligations at work, school, or at home. }\end{array}$ & $\begin{array}{l}\text { Role obligations may not exist for older adults in the same way } \\
\text { as for younger adults because of life-stage transitions, such as } \\
\text { retirement. The role obligations more common in late life are } \\
\text { caregiving for an ill spouse or family member, such as a } \\
\text { grandchild. }\end{array}$ \\
\hline $\begin{array}{l}\text { There is continued substance use despite having persistent or recurrent } \\
\text { social or interpersonal problems caused or exacerbated by the effects of the } \\
\text { substance. }\end{array}$ & $\begin{array}{l}\text { Older adults may not realize the problems they experience are } \\
\text { from substance use. }\end{array}$ \\
\hline $\begin{array}{l}\text { Important social, occupational, or recreational activities are given up or } \\
\text { reduced because of substance use. }\end{array}$ & $\begin{array}{l}\text { Older adults may engage in fewer activities regardless of } \\
\text { substance use, making it difficult to detect. }\end{array}$ \\
\hline $\begin{array}{l}\text { There is recurrent substance use in situations in which it is physically } \\
\text { hazardous. }\end{array}$ & $\begin{array}{l}\text { Older adults may not identify or understand that their use is } \\
\text { hazardous, especially when using substances in smaller amounts. }\end{array}$ \\
\hline $\begin{array}{l}\text { Substance use is continued despite knowledge of having a persistent or } \\
\text { recurrent physical or psychological problem that is likely to have been } \\
\text { caused or exacerbated by the substance. }\end{array}$ & $\begin{array}{l}\text { Older adults may not realize the problems they experience are } \\
\text { from substance use. }\end{array}$ \\
\hline $\begin{array}{l}\text { Tolerance is developed, as defined by either of the following: } \\
\mathbf{1} \text { A need for markedly increased amounts of the substance to } \\
\text { achieve intoxication or the desired effect }\end{array}$ & \multirow[t]{2}{*}{$\begin{array}{l}\text { Because of the increased sensitivity to substances as they age, } \\
\text { older adults will seem to have lowered rather than increase in } \\
\text { tolerance. }\end{array}$} \\
\hline $\begin{array}{l}2 \text { A markedly diminished effect with continued use of the same } \\
\text { amount of the substance }\end{array}$ & \\
\hline Withdrawal, as manifested by either of the following: & \multirow{3}{*}{$\begin{array}{l}\text { Withdrawal symptoms can manifest in ways that are more } \\
\text { "subtle and protracted." } 149 \text { Late-onset substance users may not } \\
\text { develop physiologic dependence; } \text { or nonproblematic users of } \\
\text { medications, such as benzodiazepines, may develop physiologic } \\
\text { dependence. }\end{array}$} \\
\hline The characteristic withdrawal syndrome for the substance & \\
\hline $\begin{array}{l}2 \text { The substance or a close relative is taken to relieve or avoid } \\
\text { withdrawal symptoms }\end{array}$ & \\
\hline
\end{tabular}

${ }^{a}$ SUD is defined as a medical disorder in which 2 or more of the aforementioned listed symptoms are occurring in the last 12 months. ${ }^{85}$

Adapted from Barry KL, Blow FC, Oslin DW. Substance abuse in older adults: review and recommendations for education and practice in medical settings. Subst Abus 2002;23(Suppl 3):105-31; and Data from American Psychiatric Association. Diagnostic and statistical manual of mental disorders. 5th edition. Arlington (VA): American Psychiatric Publishing; 2013. p. 491. 


\section{Table 2}

Categorization of substance use among older adults

\begin{tabular}{|ll|}
\hline Abstinence & No drinking at all and no use of illicit drugs \\
\hline Low-risk use & $\begin{array}{l}\text { Drinking within safety guidelines (7 standard drinks per week, no more than 2 drinks on any one occasion) } \\
\text { Only appropriate/prescribed use of prescription or over-the-counter medications } \\
\text { No guidelines for low-risk use for illicit drugs }\end{array}$ \\
\hline $\begin{array}{l}\text { At-risk use (also } \\
\text { referred to as unhealthy } \\
\text { or hazardous use) }\end{array}$ & $\begin{array}{l}\text { Drinking beyond safety guidelines; drinking while taking medications in which consuming alcohol is } \\
\text { contraindicated } \\
\text { Intentional or unintentional off-label use of prescription or over-the-counter medications; taking medication, even } \\
\text { once in awhile, that is not prescribed directly for that person } \\
\text { Any use of illicit substances (primarily because these substance are not quality controlled or standardized) }\end{array}$ \\
\hline Problem use & $\begin{array}{l}\text { Substance use that results in social, medical, or psychological consequences, regardless of quantity or frequency of } \\
\text { substance use }\end{array}$ \\
Problem user may or may not meet criteria for SUD
\end{tabular}

